\title{
Complications after plate fixation and elastic stable intramedullary nailing of dislocated midshaft clavicle fractures: a retrospective comparison
}

\author{
Frans-Jasper Wijdicks • Marijn Houwert • Marcel Dijkgraaf • Diederik de Lange • \\ Koen Oosterhuis • Geertjan Clevers • \\ Egbert-Jan Verleisdonk
}

Received: 2 May 2012 / Accepted: 25 June 2012 / Published online: 31 July 2012

(C) The Author(s) 2012. This article is published with open access at Springerlink.com

\begin{abstract}
Purpose The incidence of operative treatment of dislocated midshaft clavicle fractures (DMCF) is rising due to unsatisfactory results after non-operative treatment. Knowledge of complications is important for selection of the surgical technique and preoperative patient counselling. The aim of this study is to compare complications after plate fixation and elastic stable intramedullary nailing (ESIN) with a titanium elastic nail (TEN) for DMCF.

Methods A retrospective analysis of our surgical database was performed. From January 2005 to January 2010, 90 patients with DMCF were treated with plate fixation or ESIN. Complications were evaluated in both treatment groups and subsequently compared.

Results Seven implant failures occurred in six patients $(14 \%)$ of the plate group and one implant failure $(2.1 \%)$ was seen in the ESIN group $(p=0.051)$. Major revision surgery was performed in five cases in the plate group $(11.6 \%)$ and in one case $(2.1 \%)$ in the ESIN group $(p=0.100)$. Three refractures $(7.0 \%)$ were observed in the plate group after removal of the implant against none in the ESIN group $(p=0.105)$. Six minor revisions
\end{abstract}

F.-J. Wijdicks $(\bowtie) \cdot$ M. Houwert $\cdot$ K. Oosterhuis $\cdot$ G. Clevers $\cdot$

E.-J. Verleisdonk

Department of Surgery, Diakonessenhuis Utrecht,

Utrecht, The Netherlands

e-mail: fjgwijdicks@gmail.com

\section{Dijkgraaf}

Clinical Research Unit, Academic Medical Centre Amsterdam, Amsterdam, The Netherlands

D. de Lange

Department of Surgery, Ruwaard van Putten Ziekenhuis,

Spijkenisse, The Netherlands
$(13 \%)$ were reported in the ESIN group and none were reported in the plate group $(p=0.027)$.

Conclusions Compared to other studies we report higher rates of refracture $(7.0 \%)$, major revision surgery $(11.6 \%)$ and implant failure $(14.0 \%)$ after plate fixation. The frequency of implant failures differed almost significantly for patients treated with plate fixation compared to ESIN. Furthermore, a tendency towards refracture after implant removal and major revision surgery after plate fixation was observed.

\section{Introduction}

Clavicle fractures occur commonly; between 2.6 and $10 \%$ of all fractures are clavicle fractures [1]. Operative treatment for dislocated midshaft clavicle fractures (DMCF) is increasing due to reported unsatisfactory results after nonoperative treatment [2-4]. Two recently published randomised trials have proven the superiority of both plate fixation and elastic stable intramedullary nailing (ESIN) over non-operative treatment for DMCF in terms of functional outcome and pain relief $[5,6]$.

The two most commonly used techniques for operative treatment of DMCF are plate fixation and ESIN [7]. Plate fixation results in a biomechanically stable construction allowing early mobilisation and providing for fracture compression. Long-term outcome and experience with this procedure have been well documented [8]. Complications associated with plate fixation are refracture of the clavicle after implant removal and wound infection $[9,10]$.

ESIN is a relatively new and technically more demanding technique [7]. If closed fracture reduction is possible, ESIN has the advantage of maintaining an intact fracture haematoma which could speed up fracture healing. If open fracture 
reduction is necessary, surgical incisions are in general smaller in comparison to plate fixation resulting in improved cosmetic results. In addition, smaller incisions may result in lower infection rates $[6,11]$. Possible disadvantages of ESIN are medial nail protrusion and the need for implant removal requiring a second operation $[11,12]$.

Knowledge of possible complications is essential on the appropriate surgical technique and preoperative patient counselling. A recent Cochrane review showed that comparative studies of different techniques for operative treatment of DMCF are lacking [13]. The aim of this study is to retrospectively compare complications after plate fixation and ESIN with a titanium elastic nail (TEN) for DMCF.

\section{Materials and methods}

A retrospective analysis of data from the surgical database at our hospital was performed. The Diakonessenhuis is a level 2 trauma centre and a regional teaching hospital. All monotrauma patients who underwent operative treatment for a DMCF between January 2005 and July 2010 were eligible for inclusion. This inclusion period allowed for another year of follow-up postoperatively. Dislocation was defined as at least one shaft width difference in height between the fracture parts, regardless of the reduction.

The following exclusion criteria were used: (1) patients with pre-existent morbidity concerning the arm, shoulder or hand, (2) open fractures, (3) pathological fractures, (4) presence of neurovascular injury and (5) fractures older than one month or non-unions.

\section{Operative treatment}

The operations were performed or supervised by one of the trauma surgeons (DL, KO, GJC, EV). The choice of the procedure was based on either the surgeon's or patient's preference.

\section{Operative technique: plate fixation}

Patients were treated according to the principles set by the AO Foundation. Patients were administered prophylactic antibiotics. A compression plate with additional interfragmentary lag screws or a bridging plate in cases of severe comminution were used for different kinds of fracture types. A transverse incision was made over the fracture site and in all cases the plate was positioned on the anterior superior surface of the clavicle. Different types of plates were used, which were provided by Synthes ${ }^{\circledR}$ b.v., Zeist, Netherlands. In the beginning of the study period reconstruction plates with the corresponding screws were used, later on small fragment locking plates with the corresponding screws became available and for the remaining time of the study these plates and screws were used.

\section{Operative procedure ESIN}

Patients were administered prophylactic antibiotics. A small skin incision was made approximately $1 \mathrm{~cm}$ lateral to the sternoclavicular joint. For ESIN a Synthes ${ }^{\circledR}$ TEN was used. A TEN was inserted with a diameter varying from 2 to $3.5 \mathrm{~mm}$, depending on the width of the bone. Closed reduction, initially fixed with two percutaneously pointed reduction (Weber) clamps, was performed and confirmed by fluoroscopy. If closed reduction failed, an additional small incision was made above the fracture site for direct manipulation of the main fragments. After complete introduction of the TEN into the lateral fragment, the fracture was compressed and the TEN was cut as short as possible at the medial end.

\section{Postoperative management}

The choice of postoperative management was based on the surgeon's preference, but patients generally received a sling while being encouraged to start early mobilisation if pain permitted.

\section{Complications}

The complications were divided into two groups: major and minor complications.

Major complications

The following complications were regarded as major (Table 1): non-union, symptomatic malunion, refracture after implant removal, deep infections or breakage of the implant.

Non-union was defined as an unsuccessful healing of the bone after six months that clinically could be associated with pain and was visible on the radiograph as a gap between the fracture parts. Symptomatic malunion was defined as an incorrect anatomical position of the clavicle in comparison to the (healthy) side resulting in pain symptoms or a loss of function of the shoulder. Implant-related problems such as breakage were determined on the radiographs. Deep infection was defined as infection requiring implant removal. Refracture was defined as a fracture of the clavicle after implant removal and diagnosis was based on clinical symptoms and radiographs.

Minor complications

The following complications were considered as minor (Table 1): (oral) antibiotics for a wound infection or cutting the protruding end of the TEN under a local 
Table 1 Major and minor complications

\begin{tabular}{ll}
\hline Major complications & Minor complications \\
\hline Non-union & Superficial infection \\
(Symptomatic) malunion & Pain after 6 months \\
Implant fracture (breakout) & Temporary brachial plexus lesion \\
Major revision surgery & Hyperaesthesia \\
Deep infection & Plate irritation \\
Refracture after implant removal & Medial TEN protrusion \\
& Lateral TEN protrusion \\
& Minor revision surgery \\
& (shortening of TEN) \\
\hline
\end{tabular}

anaesthetic in case of medial irritation or skin perforation. Other minor complications were deep infections not requiring implant removal or debridement, migration and telescoping (for ESIN), angulation of the implant without persistent symptoms and neurovascular problems.

Infection was defined as redness, swelling, purulent discharge, a positive wound culture and/or when prescription of antibiotics was given. Irritation (of the skin) was assessed clinically and caused by prominence of the implant material or in case of the TEN medial or lateral protrusion. Migration was defined as the medial or lateral displacement of the TEN without movement of the fracture parts also resulting in medial or lateral protrusion. Telescoping was defined as displacement of the fracture parts and the TEN. Pain was considered significant if it was still present after six months.

When treated with ESIN the TEN was always removed after four months and/or if consolidation was achieved. Plate fixation was only considered for removal after consolidation and if patients experienced irritation or nuisance caused by the implant, or by explicit request of the patient. Consolidation and appropriate time of removal were determined by the treating surgeon by examining radiographs and the clinical condition of the patient.

\section{Statistical analysis}

Descriptives were reported as mean and standard deviation (SD) or as median and interquartile range (IQR), depending on normal or non-normal distributions of the data, respectively. An independent samples $t$ test was performed to assess differences in age between groups; the Mann-Whitney $\mathrm{U}$ test was performed in case of total follow-up duration; the chi-square test was used in case of gender, fracture side, trauma mechanism and $\geq 1$ irritation(s); and Fisher's exact test was used in case of AO Classification, neurovascular injury, imminent skin perforation, $\geq 1$ implant failure(s), major surgical revision, refractures, superficial infection and minor revision surgery. Kaplan-Meier survival analysis was performed to assess differences in time to removal of TEN or plate fixation, with non-removal considered as censored observation. The level of significance was set at $p<0.05$. Statistical analyses were performed using SPSS software (version 17.0.0, Chicago, IL, USA).

\section{Approval}

In accordance with the legal department of the Diakonessenhuis Utrecht and the local Ethics Commission, individual patient approval was not required due to full anonymity of the included patients and the retrospective study design.

\section{Results}

According to the inclusion and exclusion criteria 90 patients could be included in the analysis (Fig. 1); 43 patients were treated by plate fixation and 47 patients were treated using ESIN. On average, patients in the plate group were 39.4 (SD $14.1)$ years of age and older $(p=0.049)$ than patients in the ESIN group, who were 33.1 (SD 15.6) years of age (Table 2). In the ESIN group closed fracture reduction was performed in seven cases (14.9\%), and open fracture reduction was performed in the remaining 40 patients $(85.1 \%)$. The median follow-up time of all patients was seven months (IQR 4-13 months). The plate group had a median follow-up time of eight months (IQR 2-13 months). A median follow-up time of six months (IQR five to 12 months) was observed in the ESIN group.

\section{Major complications}

\section{Implant failure}

Seven implant failures occurred in six patients (14.0\%) of the plate group. One implant failure was seen in the ESIN group (2.1\%) ( $p=0.051$, Table 3$)$. All implant fractures occurred within three months of the primary surgical procedure (Fig. 2).

Three of these broken plates were revised with plate fixation and supplementary cancellous bone graft. The remaining four implant failures in the plate group were treated conservatively in all cases after removal of the implant. One of these patients recovered with a slightly impaired shoulder function, and the other patients all healed uneventfully. The implant failure in the ESIN group (Fig. 3) was revised using plate fixation and supplementary bone graft and healed uneventfully.

\section{Major revision surgery}

Major revision surgery was performed in five cases in the plate group (11.6\%), and one major revision surgery was 
Fig. 1 Flowchart: selection of patient group

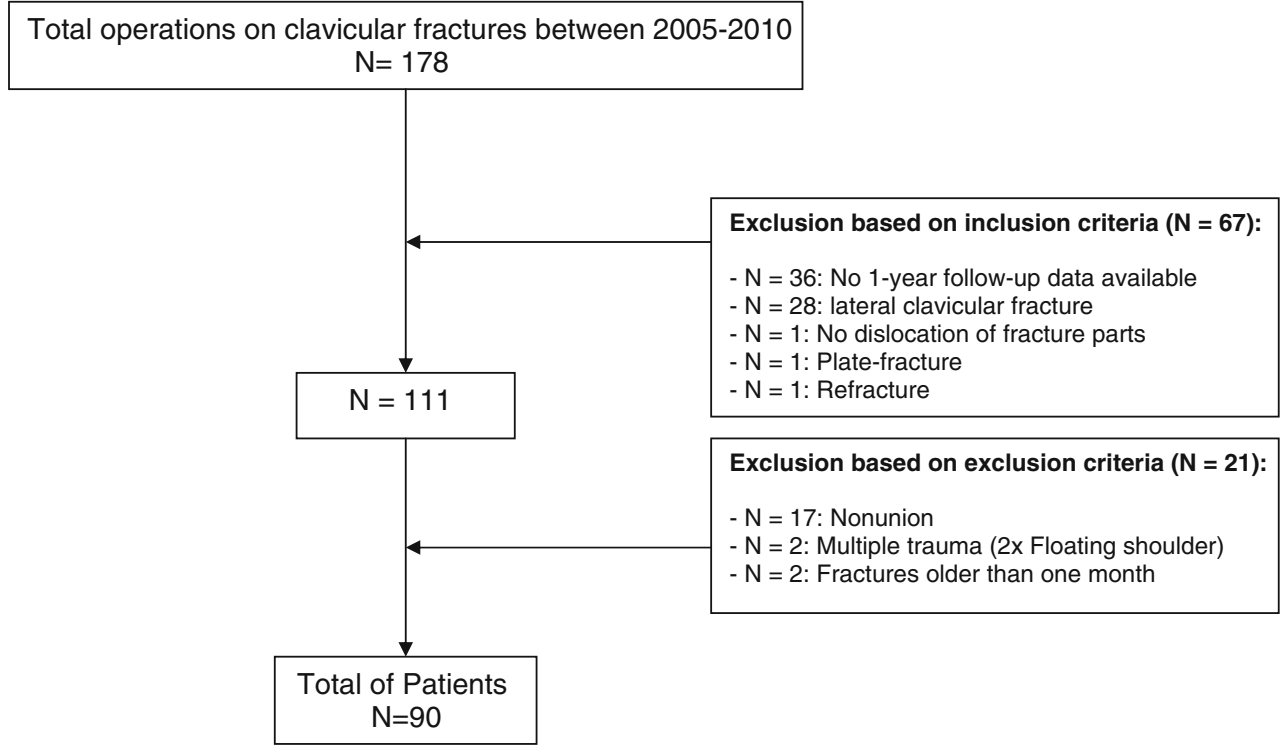

performed in the ESIN group (2.1\%) ( $p=0.100$, Table 3). Three revision operations were performed in the plate group as mentioned above due to implant failure (see Implant failure). One major revision operation in the plate group was the treatment of a refracture after removal of the implant (see Refractures). The last major revision operation was

Table 2 Baseline characteristics, follow-up duration and time to removal for both treatment groups

\begin{tabular}{|c|c|c|c|c|}
\hline & & Plate group, $n=43$ & ESIN group, $n=47$ & $p$ value \\
\hline Age, years (mean $\pm \mathrm{SD}$ ) & & $39.4 \pm 14.1$ & $33.1 \pm 15.6$ & $p=0.049$ \\
\hline Gender, $n(\%)$ & $\begin{array}{l}\text { Male } \\
\text { Female }\end{array}$ & $\begin{array}{l}33(77) \\
10(23)\end{array}$ & $\begin{array}{l}33(70) \\
14(30)\end{array}$ & $p=0.48$ \\
\hline Fracture side, $n(\%)$ & $\begin{array}{l}\text { Right } \\
\text { Left }\end{array}$ & $\begin{array}{l}20(47) \\
23(54)\end{array}$ & $\begin{array}{l}19(40) \\
28(60)\end{array}$ & $p=0.56$ \\
\hline AO Classification, $n(\%)$ & $\begin{array}{l}\text { A1 } \\
\text { A2 } \\
\text { A3 } \\
\text { B1 } \\
\text { B2 } \\
\text { B3 } \\
\text { C1 } \\
\text { C2 } \\
\text { C3 }\end{array}$ & $\begin{array}{l}- \\
11(26) \\
8(19) \\
1(2) \\
17(4 \%) \\
2(5) \\
1(2) \\
3(7) \\
-\end{array}$ & $\begin{array}{l}- \\
22(47) \\
7(15) \\
0 \\
14(30) \\
4(9) \\
0 \\
0 \\
-\end{array}$ & $p=0.11$ \\
\hline Trauma mechanism, $n(\%)$ & $\begin{array}{l}\text { Traffic accident } \\
\text { Sports } \\
\text { Fall } \\
\text { Unknown }^{\mathrm{a}}\end{array}$ & $\begin{array}{l}9(21) \\
18(42) \\
13(30) \\
3(7)\end{array}$ & $\begin{array}{l}12(26) \\
18(38) \\
12(26) \\
5(11)\end{array}$ & $p=0.81$ \\
\hline Neurovascular injury, $n(\%)$ & Unknown ${ }^{\mathrm{a}}$ & $\begin{array}{l}0 \\
3(7)\end{array}$ & $\begin{array}{l}2(4) \\
9(19)\end{array}$ & $p=0.23$ \\
\hline Imminent skin perforation, $n(\%)$ & Unknown $^{\mathrm{a}}$ & $\begin{array}{l}1(2) \\
3(7)\end{array}$ & $\begin{array}{l}2(4) \\
9(19)\end{array}$ & $p=0.61$ \\
\hline Follow-up time, months (median, IQR) & & $8(2-13)$ & $6(5-12)$ & $p=0.76$ \\
\hline Time to removal, months (median, IQR) & & $11(7-15)$ & $5(4-6)$ & $p=<0.001$ \\
\hline
\end{tabular}

TEN titanium elastic nail, SD standard deviation, AO Classification Müller AO Classification for Fractures-Long Bones, ESIN elastic stable intramedullary nailing

${ }^{a}$ Was not reported in documentation 
Table 3 Major and minor complications in both treatment groups

\begin{tabular}{|c|c|c|c|}
\hline Major complications & Plate group, $n=43$ & ESIN group, $n=47$ & $p$ value \\
\hline At least 1 implant failure ${ }^{\mathrm{a}}, n(\%)$ & $6(14)$ & $1(2)$ & $p=0.051$ \\
\hline Major revision surgery, $n(\%)$ & $5(12)$ & $1(2)$ & $p=0.100$ \\
\hline Refracture after implant removal, $n(\%)$ & $3(7)$ & 0 & $p=0.105$ \\
\hline \multicolumn{4}{|l|}{ Minor complications } \\
\hline Superficial infection, $n(\%)$ & $1(2)$ & $4(9)$ & $p=0.363$ \\
\hline At least one irritation, $n(\%)$ & $19^{\mathrm{b}}(44)$ & $29^{\mathrm{b}}(62)$ & $p=0.096$ \\
\hline Pain after 6 months, $n(\%)$ & $4(9)$ & $2(4)$ & \\
\hline Temporary brachial plexus lesion, $n(\%)$ & 0 & $2(4)$ & \\
\hline Hyperaesthesia, $n(\%)$ & $3(7)$ & 0 & \\
\hline Plate irritation, $n(\%)$ & $17(40)$ & & \\
\hline Medial TEN protrusion, $n(\%)$ & & $23(49)$ & \\
\hline Lateral TEN protrusion, $n(\%)$ & & $3(6)$ & \\
\hline Minor revision surgery (shortening of TEN), $n(\%)$ & 0 & $6(13)$ & $p=0.027$ \\
\hline
\end{tabular}

TEN titanium elastic nail, ESIN elastic stable intramedullary nailing

${ }^{a}$ One patient experienced two implant fractures

${ }^{\mathrm{b}}$ Some patients experienced more than one irritation problem

performed due to a complicated removal of the implant, requiring the use of a carbide drill in an additional operation. The major revision surgery in the ESIN group was due to implant failure and revised with plate fixation and spongiosa transplantation (see Implant failure).

\section{Refractures}

Three refractures $(7.0 \%)$ were observed in the plate group after removal of the implant against none in the ESIN group $(p=0.105$, Table 3$)$. All refractures occurred within 2 months after removal of the implant. Two refractures were treated conservatively and one refracture was treated with plate fixation (see Major revision surgery); all three healed uneventfully.

\section{Other major complications}

No other major complications such as bone healing problems or deep infections occurred.

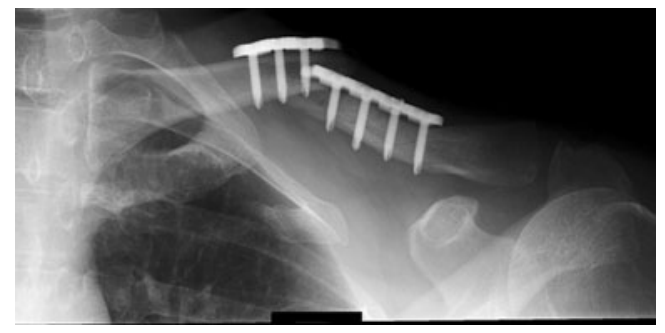

Fig. 2 Example of a broken 3.5-mm reconstruction plate
Minor complications

Six minor revisions ( $13 \%$ ) were reported in the ESIN group and none were reported in the plate group $(p=0.027$, Table 3). The definition of minor revisions is cutting the protruding medial end of the TEN under a local anaesthetic. These procedures were performed as a result of irritation of the implant (three patients) and medial skin perforation (three patients). One of the patients with medial skin perforation was also diagnosed with superficial wound infection, which was treated with oral antibiotics and healed uneventfully.

\section{Removal}

In the ESIN group 45 TEN of the total 47 TEN were removed. In the plate group 27 patients (total of 43 patients) underwent removal of the implant material. The median time until removal in all 72 patients was six months (IQR 4-11). In the ESIN group the implants were removed at a median of five months (IQR 4-6). Plates were removed at a median of 11 months (IQR 7-15) $(p<0.001$, Table 2).

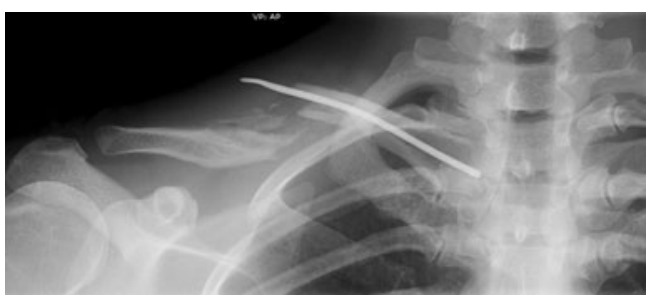

Fig. 3 Example of implant failure of a TEN 


\section{Discussion}

Implant failure just fell short of being significantly more frequently observed after plate fixation $(p=0.051)$. Similarly, refracture after implant removal and major revision surgery just tended to prevail more often after plate fixation. Moreover, $80.0 \%$ of the revision procedures were due to implant failure. Minor revision surgery on the other hand was more frequently observed after $\operatorname{ESIN}(p=0.027)$.

Compared to other studies we report higher rates of refracture $(7.0 \%)$, major revision surgery $(11.6 \%)$ and implant failure $(14.0 \%)$ after plate fixation. Ferran et al. reported no implant failures [14]. The Canadian Orthopaedic Trauma Society reported one $(1.6 \%)$ case of early mechanical failure, Chen et al. reported $7.1 \%$ implant failure and Liu et al. reported an implant failure rate of $8.5 \%[5,15,16]$. Our results are comparable with the results of Böstman et al., who reported an implant failure rate of $14.6 \%$ [17]. Implant removal after plate fixation resulted in refracture in $1.0-5.3 \%$ [10, 17-19].

Similar results have been found in the literature regarding minor complications in plate fixation [20], and the incidences of major and minor complications after ESIN seem to comply with estimates from literature elsewhere [21].

Theoretically, complications after plate fixation differ from complications after intramedullary fixation. Plate fixation provides a rigid fixation, originally intended to achieve primary bone healing. Fracture healing occurs without much periosteal ossification, and after fracture healing the plate might still contribute to the mechanical strength of the fixation. Therefore, implant removal might reduce mechanical strength which could explain the slightly increased refracture rates. Another explanation for the tendency of slightly more refractures might be the screw holes after implant removal. These weak spots could potentially initiate a refracture in small clavicles.

Fixation using an intramedullary device results in secondary bone healing. Secondary bone healing is achieved through periosteal ossification, and after fracture healing the intramedullary device does not continue to contribute to the mechanical strength of the fixation. Therefore, intramedullary fixation might show less refractures after removal of the implant.

Implant failures can also be explained by this mechanism. An intramedullary device moves along with the slight movements of the bone and will restore it to its original form. Plate fixation is rigid and does not move. When excessive movement occurs, the plate might bend or break.

The main problem after ESIN is medial protrusion causing irritation or skin perforation resulting in minor revision surgery. In the literature, medial protrusion is reported in the range of 5.2-38.8 \% [6, 15, 22, 23]. This minor complication can be prevented by anatomical reduction and fixation of the fracture to prevent telescoping. Early abduction of the arm should also be considered as a cause of medial protrusion of the TEN. Patients should be advised not to abduct the arm over $90^{\circ}$ in the first two weeks postoperatively. Another option of reducing medial protrusion is the use of medial end caps. Frigg et al. showed a reduction in medial protrusion rates by using an end cap for TEN [23].

For plate fixation a larger incision is made, which results in a higher risk of infection and probably less cosmetic satisfaction. In this study no significant differences in infection rates between the two groups were observed.

This study is limited by its retrospective design, resulting for instance in an older patient group receiving plate fixation. The impact of the plate fixation group being older could not be assessed in this relatively small patient group. Further, shoulder function and cosmetic appearance were not adequately documented. Therefore, results after both procedures regarding shoulder function and cosmetic appearance could not be compared. However, according to comparative studies on this subject, no significant differences in shoulder function and cosmetic appearance have yet been reported between both techniques [16, 17, 24].

During the study period, different types of plate fixation were used according to fracture type or surgeon's preference. This might limit the general application of the complications in the plate group. The reason for using different plates was the availability of the types of plates. At the start of this study period reconstruction plates were used, and later the small fragment locking plates became available and were used. However, the main goal of this study was to compare complications after two principles of osteosynthesis for DMCF: plate fixation and intramedullary fixation with ESIN.

Moreover, the retrospective study design may have hampered a complete record of complications that may have occurred during follow-up, but were treated and followed up elsewhere, at another hospital. Due to the surgeon's preference of treatment method and the retrospective design we also encountered a difference in treatment policy for different types of fractures. Simple fractures (i.e. A2 or B2, Table 2) had a greater possibility of being treated with ESIN than complex fractures.

Currently a randomised controlled study is being performed at the Diakonessenhuis Utrecht comparing plate fixation and intramedullary fixation in DMCF (POP study [25]). The goal of this study is to provide a better insight into results and the complications after both treatments [26]. In this study the frequency of implant failures differed almost significantly for patients treated with plate fixation compared to ESIN. Furthermore, a tendency towards refracture after implant removal and major revision surgery after plate fixation was observed. 
Conflict of interest The authors declare that they have no conflict of interest.

Open Access This article is distributed under the terms of the Creative Commons Attribution License which permits any use, distribution, and reproduction in any medium, provided the original author(s) and the source are credited.

\section{References}

1. O’Neill BJ, Hirpara KM, O’Briain D, McGarr C, Kaar TK (2011) Clavicle fractures: a comparison of five classification systems and their relationship to treatment outcomes. Int Orthop 35(6):909-914

2. Hill JM, LA McGuire Crosby (1997) Closed treatment of displaced middle-third fractures of the clavicle gives poor results. $\mathrm{J}$ Bone Joint Surg Br 79:537-539

3. Postacchini R, Gumina S, Farsetti P, Postacchini F (2010) Longterm results of conservative management of midshaft clavicle fracture. Int Orthop 34(5):731-736

4. Zlowodzki M, Zelle BA, Cole PA, Jeray K, McKee MD (2005) Treatment of acute midshaft clavicle fractures: systematic review of 2144 fractures: on behalf of the Evidence-Based Orthopaedic Trauma Working Group. J Orthop Trauma 19:504-507

5. Canadian Orthopaedic Trauma Society (2007) Nonoperative treatment compared with plate fixation of displaced midshaft clavicular fractures. A multicenter, randomized clinical trial. J Bone Joint Surg Am 89(1):1-10

6. Smekal V, Irenberger A, Struve P, Wambacher M, Krappinger D, Fralinger FS (2009) Elastic stable intramedullary nailing versus nonoperative treatment of displaced midshaft clavicular fracturesa randomized, controlled, clinical trial. J Orthop Trauma 23:106-112

7. Smekal V, Oberladstaetter J, Struve P, Krappinger D (2009) Shaft fractures of the clavicle: current concepts. Arch Orthop Trauma Surg 129:807-815

8. Golish SR, Oliviero JA, Francke EI, Miller MD (2008) A biomechanical study of plate versus intramedullary devices for midshaft clavicle fixation. J Orthop Surg Res 16(3):28

9. Verborgt O, Pittoors K, Van Glabbeek F, Declercq G, Nuyts R, Somville J (2005) Plate fixation of middle-third fractures of the clavicle in the semi-professional athlete. Acta Orthop Belg 71 (1):17-21

10. Poigenfürst J, Rappold G, Fisher W (1992) Plating of fresh clavicular fractures: results of 122 operations. Injury 23(4):237-241

11. Smekal V, Irenberger A, El Attal R, Oberladstaetter J, Krappinger D, Kralinger F (2011) Elastic stable intramedullary nailing is best for mid-shaft clavicular fractures without comminution: results in 60 patients. Injury 42(4):324-329

12. Chen Y-F, Zeng B-F, Chen Y-J, Wang H, Xue J, Chai Y et al (2010) Clinical outcomes of midclavicular fractures treated with titanium elastic nails. Can J Surg 53(6):379-384
13. Lenza M, Belloti JC, Gomes Dos Santos JB, Matsumoto MH, Faloppa F (2009) Surgical interventions for treating acute fractures or non-union of the middle third of the clavicle. Cochrane Database Syst Rev 4:CD007428

14. Ferran NA, Hodgson P, Vannet N, Williams R, Evans RO (2010) Locked intramedullary fixation vs plating for displaced and shortened mid-shaft clavicle fractures: a randomized clinical trial. J Shoulder Elbow Surg 19:783-789

15. Chen YF, Wei HF, Zhang C, Zeng BF, Zhang CQ, Xue JF et al (2012) Retrospective comparison of titanium elastic nail (TEN) and reconstruction plate repair of displaced midshaft clavicular fractures. J Shoulder Elbow Surg 21:495-501. doi:10.1016/ j.jse.2011.03.007

16. Liu HH, Chang CH, Chia WT, Chen CH, Tarng YW, Wong CY (2010) Comparison of plates versus intramedullary nails for fixation of displaced midshaft clavicular fractures. J Trauma 69(6): E82-E87

17. Böstman O, Manninen M, Pihlajamäki H (1997) Complications of plate fixation in fresh displaced midclavicular fractures. J Trauma 43:778-783

18. VanBeek C, Boselli KJ, Cadet ER, Ahmad CS, Levine WN (2011) Precontoured plating of clavicle fractures: decreased hardwarerelated complications? Clin Orthop Relat Res 469(12):3337-3343

19. Assobhi JEH (2011) Reconstruction plate versus minimal invasive retrograde titanium elastic nail fixation for displaced midclavicular fractures. J Orthop Traumatol 12(4):185-192. doi:10.1007/ s10195-011-0158-7

20. Wijdicks FJG, van der Meijden OAJ, Millet PJ, Verleisdonk EJMM, Houwert RM (2012) Systematic review of the complications of plate fixation of clavicle fractures. Arch Orthop Trauma Surg 132(5):617-625

21. Wijdicks FJG, Houwert RM, Millet PJ, Verleisdonk EJMM, van der Meijden OAJ (2012) Systematic review of complications after intramedullary fixation for displaced midshaft clavicle fractures. Can J Shoulder Surg. Accepted for publication

22. Jubel A, Andermahr J, Schiffer G, Tsironis K, Rehm KE (2003) Elastic stable intramedullary nailing of midclavicular fractures with a titanium nail. Clin Orthop Relat Res 408:279-285

23. Frigg A, Rillmann P, Perren T, Gerber M, Ryf C (2009) Intramedullary nailing of clavicular midshaft fractures with the titanium elastic nail: problems and complications. Am J Sports Med 37(2):352-359

24. Lee YS, Huang HL, Lo TY, Hsieh YF, Huang CR (2008) Surgical treatment of midclavicular fractures: a prospective comparison of Knowles pinning and plate fixation. Int Orthop 32:541-545

25. Wijdicks FJG, Houwert RM, Dijkgraaf MGW, De Lange DH, Meylaerts SAG, Verhofstad MHJ, Verleisdonk EJM (2011) Rationale and design of the plate or pin (POP) study for dislocated midshaft clavicular fractures: study protocol for a randomised controlled trial. Trials 12:177

26. Houwert RM, Wijdicks FJ, Steins Bisschop C, Verleisdonk EJ, Kruyt M (2012) Plate fixation versus intramedullary fixation for displaced mid-shaft clavicle fractures: a systematic review. Int Orthop 36(3):579-585 